\title{
Estimation of current population mean using two-occasion successive sampling with one auxiliary variable
}

\author{
R. Zoramthanga \\ Department of Statistics, Pachhunga University College, Aizawl 796ooI, India
}

\begin{abstract}
In this study, two-occasion successive sampling for ratio-to-regression estimator was used to determine the current estimate of the population mean using only the matched part and one auxiliary variable, which is available on both the occasions. The data used were based on the total number of female workers in villages in Mizoram with the total number of literate female in villages in Mizoram as an auxiliary variables. The data were gotten from Census of India 2001 and 2011. The optimum mean square error of the combined ratio-to-regression and ratio estimator has been compared with (i) the optimum mean square error of the chaintype ratio estimator (ii) mean per unit estimator and (iii) combined estimator when no auxiliary information is used at any occasion. This result showed that the combined ratio-toregression and ratio estimator is more efficient than the other three existing estimators.
\end{abstract}

Key words: Ratio-to-regression estimator, two-occasion successive sampling, mean square error (MSE), relative efficiency.

\section{Introduction}

In a sample survey, it is often seen that sample surveys are not limited to one time enquiries. If the value of study character of a finite population is subject to change over time, a survey carried out on a single occasion will provide information about the characteristics of the surveyed population on the given occasion only and cannot give any information on the nature or the rate of change of the characteristics over all the occasions or more recent occasion. Data regarding changing properties of the population of cities or countries, such as unemployment statistics, are collected regularly on a sample basis, to estimate the change from one occasion to the next or to estimate the average over certain period. An important aspect of continuous survey is the structure of the sample on each occasion. To meet these requirements, successive sampling provides a strong tool for generating reliable estimates on different occasions. When the same population is sampled repeatedly the sampler is in an ideal position to make realistic estimates, both of costs and of variances and to apply the technique that leads to optimum efficiency of sampling. ${ }^{1}$ The successive sampling is a known technique that can be used in longitudinal survey to estimate the population parameters and measurements of difference or change of a study variable.

Successive sampling is used extensively in 
applied sciences, social sciences and economic research. There are several types of procedures to adopt for estimating the population parameters: sion.

The same sample may be used on each occa-

A new sample may be taken on each occasion.

A part of the sample may be retained while the remainder of the sample may be drawn afresh.

A sub sample of the original sample on the second occasion. ${ }^{2}$

Generally, the main objective of successive surveys is to estimate the change with a view to study the effects of the forces acting on the population. ${ }^{3}$

Here some conditions to consider are that;

For estimating change from one occasion to the next, it may be best to retain the same sample on each occasion

For estimating the mean on each occasion, it may be best to draw a fresh sample on each occasion, and

If it is desired to estimate the mean on each occasion and also the change from one occasion to the next, it may be best to retain part of the sample and draw the remainder of the sample afresh.

A large part of sample survey theory has been directly motivated by practical problems encountered in the design and analysis of large scale sample surveys. Major advances have taken place in handling both sampling and nonsampling errors as well as data collection and processing. Since then considerable amount of work has been done in the direction of providing improved estimators in survey sampling. The sampling on two-occasion was first considered by Jessen ${ }^{4}$ for the estimation of current population mean. Patterson ${ }^{2}$ studied a method of partial matching to estimate the mean on each occasion and also the change from one occasion to the next.

Rao and Graham, ${ }^{5}$ Gupta, ${ }^{6}$ and Sen $^{7}$ developed estimators for the population mean on the current occasion using information on two auxiliary variables available on the previous occasion.
Sen $^{8,9}$ extended his work for several auxiliary variates. Singh and Talwar ${ }^{10}$ and Singh and Singh ${ }^{11}$ used the auxiliary information on current occasion for estimating the current population mean in two occasion successive sampling.

Singh and Priyanka ${ }^{12-14}$ proposed varieties of chain-type ratio, difference and regression estimators for estimating the population mean at current (second) occasion in two occasion successive sampling.

Eze et al. ${ }^{15}$ studied successive sampling for regression estimation to determine the current estimate of the population mean, minimum variance, maximum precision, estimate of change between the two successive occasions under consideration and estimate of average over the period of two occasions. Also the used of successive sampling to determine the current estimate of the mean, minimum variance, estimate of change between the two successive occasions and estimate of average over the period of the two occasions was studied. ${ }^{16}$

The intention of this paper is therefore to find out if the combined ratio-to-regression and ratio estimator ${ }^{17}$ has a greater efficiency than the chain-type ratio estimator, ${ }^{18}$ mean per unit estimator and combined estimator when no auxiliary information is used at any occasion suggested by Cochran. ${ }^{1}$

\section{Materials and Method}

\section{Data used}

The data used for this study is from the records of the total number of female workers and the total number of literate female in villages in the state of Mizoram, Census of India 2001 and $2011 .^{19}$

\section{Methodology}

The variables $\mathrm{x}(\mathrm{y})$ were defined as the total number of female workers in villages in the state of Mizoram, India in 2001 (2011) and $z$ is defined as an auxiliary variable which is the total number of literate female in villages in the 
state of Mizoram, India.

Consider a population consisting of $\mathrm{N}$ units. Let a character under study on the first (second) occasion be denoted by $\mathrm{x}(\mathrm{y})$, respectively. It is assumed that the information on an auxiliary variable $\mathrm{z}$ is available on the first as well as on the second occasion. It is also assumed that the population to be large enough, and the sample size is constant on each occasion. Using simple random sampling without replacement (SRSWOR) select a sample of size $\mathrm{n}$ on the first occasion. Of these $\mathrm{n}$ units, a sub-sample of size $\mathrm{m}=\mathrm{n} \lambda$ is retained on the second occasion. This sub-sample is supplemented by selecting an SRSWOR of $u=(n-m)=n \mu$ units afresh from the units that were not selected on the first occasion.

\section{Results}

From the data used, using two occasion successive sampling a random sample of 70 villages was selected from a population of 669 villages on each occasion, this comprises of 35 matched villages and 35 unmatched villages in the state of Mizoram.

Table 1 | Relative Efficiency (\%) of $\mathrm{T}_{\mathrm{p}_{1}}$ with respect to estimators $\mathrm{T}, \overline{\mathrm{y}}_{\mathrm{n}}$ and $\overline{\mathrm{y}}_{2}$.

\begin{tabular}{cccc}
\hline Estimators & Estimates & MSE & $\begin{array}{c}\text { Efficiency } \\
\%\end{array}$ \\
\hline $\mathrm{T}_{\mathrm{p}_{1}}$ & 146 & 107.49 & 100 \\
\hline $\mathrm{T}$ & 139 & 344.65 & 320.62 \\
\hline$\overline{\mathrm{y}}_{\mathrm{n}}$ & 130 & 373.54 & 347.50 \\
$\overline{\mathrm{y}}_{2}$ & 130 & 304.81 & 283.56 \\
\hline
\end{tabular}

where

$\mathrm{T}_{\mathrm{p}_{1}}$ is a combined estimator proposed by Ralte and Das, ${ }^{17}$

$\mathrm{T}$ is a combined estimator proposed by Singh, 18

$\overline{\mathrm{y}}_{\mathrm{n}}$ is mean per unit estimator, and

$\overline{\mathrm{y}}_{2}$ is a combined estimator suggested by
Cochran ${ }^{1}$ when no auxiliary information is used at any occasion.

\section{Conclusion}

From the table in the above section, the combined ratio-to-regression and ratio estimator i.e. $T_{p_{1}}$ is more efficient than the other existing three estimators viz. T, $\bar{y}_{\mathrm{n}}$ and $\overline{\mathrm{y}}_{2}$ with maximum gain in efficiency occurring while comparing with mean per unit estimator, which is very obvious. Hence, the estimator $T_{p_{1}}$ is recommended for further practical use.

\section{References}

I. Cochran, W. G. (1977). Sampling Techniques ( ${ }^{\text {rd }}$ ed.). Wiley Eastern Ltd.

2. Patterson, H. D. (1950). Sampling on successive occasions with partial replacement of units. Journal of the Royal Statistical Society 12(B), 24I - 255.

3. Singh, D. \& Chaudhary, F.S. (1986). Theory and Analysis of Sample Survey Designs (I ${ }^{\text {st }}$ ed.). New Age International (P) Ltd.

4. Jessen, R.J. (1942): Statistical investigations of a sample survey for obtaining farm facts. Journal of Agricultural Experiment Station Research Bulletin 304, I-IO4.

5. Rao, J.N.K. \& Graham, Jack E. (1964). Rotation designs for sampling on repeated occasions. Journal of American Statistical Association 59, 492-509.

6. Gupta, P.C. (1979). Sampling on two successive occasions. Journal of Statistical Research 13, 7-16.

7. Sen, A.R. (197I). Successive sampling with two auxiliary variables. Sankbya 33(B), 371-378.

8. Sen, A.R. (1972): Successive sampling with $\mathrm{p}(\mathrm{p} \geq \mathrm{I})$ auxiliary variables. The Annals of Mathematical Statistics 43, $203 \mathrm{I}-2034$.

9. Sen, A.R. (1973). Theory and application of sampling on repeated occasions with several auxiliary variables. Biometrics 29, 38I-385.

Io. Singh, P. \& Talwar, H.K. (199I). Estimation of population regression coefficient in successive sampling. Biometrical Journal 33, 599-605.

II. Singh, G.N. \& Singh, V.K. (200I). On the use of auxiliary information in successive sampling. Journal of the Indian Society of Agricultural Statistics 54(I), I-I2. 
I2. Singh, G.N. \& Priyanka, K. (2006). On the use of chaintype ratio to difference estimator in successive sampling. International Journal of Applied Mathematics and Statistics 5 (So6), 4I-49.

13. Singh, G.N. \& Priyanka, K. (2007). On the use of auxiliary information in search of good rotation patterns on successive occasions. Bulletin of Statistics and Economics I(Ao7), 42-6o.

14. Singh, G.N. \& Priyanka, K. (2008). On the use of several auxiliary variates to improve the precision of estimates at current occasion. Journal of the Indian Society of Agricultural Statistics 62(3), 253-265.

I5. Eze, S.O., Amahia, G.N., Olayiwola, O.M. \& Adewara, A.A. (2OII). Efficiency of second occasion over first occasion on successive sampling for regression estimation. Journal Mathematics Research 3(2), 235-242.
16. Anieting, A.E. \& Ezugwa, V.O. (2013). Estimation of the current occasion parameters using successive sampling approach. American Journal of Engineering Research 2 (9), 204-207.

17. Ralte, Z. \& Das, G. (2015). Ratio-to-regression estimator in successive sampling using one auxiliary variable. Statistics in Transition 16(2), 183-202.

I8. Singh, G.N. (2005). On the use of chain-type ratio estimator in successive sampling. Statistics in Transition 7 (I), 2I-26.

19. Census of India 2001 and 20II. www.cesusindiagov.in 